\title{
A lógica medicalizante nas políticas públicas de educação
}

\author{
Kelly Cristina dos Santos Silva* \\ Carla Biancha Angelucci**
}

\section{Resumo}

São inúmeros os avanços das políticas educacionais brasileiras, entretanto, é possível observar a permanência da lógica medicalizante no ideário educacional e no espaço escolar, ao serem reduzidas questóes de ordem social, econômica, política e educacional ao campo biomédico. O presente trabalho buscou compreender indícios dessa lógica medicalizante na política brasileira de Educação Especial a partir da Política Nacional de Educação Especial na perspectiva da Educação Inclusiva (2008), do Plano Nacional de Educação (2010) e do documento final da Conferência Nacional da Educação (2014), utilizando, para tanto, o paradigma indiciário de Ginzburg (1989). Os resultados revelam a existência de importantes discussóes e a criação de estratégias de superação do preconceito contra grupos historicamente marginalizados, inclusive no concernente ao público-alvo da Educação Especial. Contudo, observa-se que a permanência da lógica medicalizante nos documentos analisados, dá-se, sobretudo, em relação às terminologias emprestadas do campo da Saúde, sendo inadequadas para definir aspetos relativos ao processo de escolarizaçáo. Assim, perpetua-se o deslocamento de questóes de ordem política e institucional para aspectos individuais, medicalizando alunas/alunos, inclusive as/os que frequentam a Educação Especial. Entende-se como necessária a reconfiguração das relaçôes entre os campos da Saúde e da Educação, permitindo a construção de práticas coletivas que possam discutir as problemáticas escolares a partir do diálogo e não da sobredeterminação da Saúde pela Educação. Isso implica, também, esforço da Educação para produzir formas de compreender as/os estudantes e seus processos ensino-aprendizagem fora do eixo patologia/normalidade, afirmando radicalmente a diversidade humana como princípio, meio e fim do trabalho educativo.

Palavras-chave: Educação Especial; Medicalização; Política pública educacional.

\footnotetext{
* Doutoranda em Educação da Universidade de São Paulo, São Paulo, São Paulo, Brasil.

** Docente da Faculdade de Educação da Universidade de São Paulo, São Paulo, São Paulo, Brasil.
} 


\section{The medicalizing logic in public education policies}

\section{Abstract}

Despite the advances in the discussions about current Brazilian educational policies, it is possible to observe the permanence of the medicalizing logic in the educational ideals and in the school space, by reducing social, economic, political and educational issues for the biomedical field. The present study sought to understand the indications of this medicalizing logic in the Brazilian Special Education policy based on the analysis of the National Policy on Special Education from the perspective of Inclusive Education (2008), the National Education Plan (2010) and the end document of the national Education conference (2014), using the Ginzburg (1989) indicium paradigm. The results reveal the existence of important discussions and the creation of strategies for overcoming prejudice against historically marginalized groups. However, it is observed that the permanence of the medical logic in the documents is mainly related to the borrowed terminology of the health field, being inadequate to define aspects related to the schooling process. The displacement of political and institutional issues to individual aspects is perpetuated, medicalizing students attended by Special Education. It is understood as necessary the reconfiguration of the relations between the fields of Health and Education, allowing the construction of collective practices that can discuss the school problems from the dialogue and not from the overdetermination of Health through Education. This also implies an effort by Education to produce ways of understanding students and their teaching-learning processes outside the pathology / normality axis, radically affirming human diversity as the principle, middle and end of educational work.

Keywords: Special Education; Medicalization; Public educational policy.

\section{La lógica medicalizante en las políticas públicas de educación}

\section{Resumen}

A pesar de los avances en las discusiones sobre la Educación brasileña, es posible observar la permanencia de la lógica medicalizante en el ideario educativo y en el espacio escolar, al ser reducidas cuestiones de orden social, económico, político y educativo para el campo biomédico. El presente trabajo buscó comprender indicios de esa lógica medicalizante en la política brasileña de Educación Especial a partir del análisis de la Política Nacional de Educación Especial en la perspectiva de la Educación Inclusiva (2008), del Plan Nacional de Educación (2010) y del documento final de la Conferencia Nacional de la Educación (2014), utilizando, para tanto, el paradigma indiciario de Ginzburg (1989). Resultados: existencia de importantes discusiones y la creación de estrategias de superación del prejuicio contra grupos históricamente marginados. Se observa que la permanencia de la lógica medicalizante en 
los documentos analizados, se da sobre todo en relación a las terminologías prestadas del campo de la Salud, siendo inadecuadas para definir aspectos relativos al proceso de escolarización. Se perpetúa el desplazamiento de cuestiones de orden político e institucional para aspectos individuales, medicalizando alumnas/ alumnos. Es necesaria la reconfiguración de las relaciones entre Salud y Educación, permitiendo la construcción de prácticas colectivas sobre las problemáticas escolares a partir del diálogo y no de la sobredeterminación de la Salud por la Educación. Esto implica esfuerzo de la educación para producir formas de comprender estudiantes y procesos de enseñanza-aprendizaje fuera del eje patología/normalidad, afirmando radicalmente la diversidad humana como principio, medio y fin del trabajo educativo.

Palabras-clave: Educación Especial; Medicalización; Política pública educativa.

\section{Introdução'}

$\mathrm{Na}$ atualidade, a construção de políticas públicas em Educação Especial no Brasil trata, em primeira instância, de garantir o direito à Educação, em uma perspectiva inclusiva, a partir da garantia de acesso e permanência em classes comuns de escolas regulares e da oferta de Educação de qualidade para todas/todos, o que implica garantir condiçóes adequadas de escolarização, por meio do atendimento educacional especializado. A amplitude e o alcance das políticas se entrecruzam com diversas questôes, que abrangem desde os aspectos históricos da Educação Especial até as mais recentes discussôes sobre o impacto dos saberes biomédicos na oferta de serviços voltados para o público-alvo da Educação Especial. A política de Educaçáo Especial no país é fruto de disputas que envolvem distintos agentes sociais, entre eles, o movimento de pessoas com deficiência, grupo social que historicamente permaneceu à margem dos direitos sociais. Tais disputas pelo direito à Educação refletem o tenso panorama de luta pela garantia da dignidade humana.

A retomada dos aspectos históricos da Educação Especial no país e dos modelos de compreensão das diferenças funcionais ${ }^{2}$ possibilita ferramentas para localizarmos ainda na atualidade, a sobrevivência de pressupostos dos diferentes modelos nas políticas educacionais brasileiras, tanto aquelas voltadas para a Educação Especial quanto às políticas educacionais gerais.

Ao longo do tempo, diferentes modos de adequação a padrôes de uma pretensa normalidade foram criados e, concomitantemente, foram elaboradas formas de compreender as diferenças. $\mathrm{O}$ modelo da prescindência concebe as diferenças funcionais como expressão de um destino. Tal compreensão é dividida em dois modelos: o modelo eugênico e o modelo de marginalização. $\mathrm{O}$ primeiro, característico da Antiguidade Clássica, compreende as diferenças funcionais como fenômenos não humanos, por isso, a não preservação da vida e dos direitos, sendo a prática do infanticídio bastante recorrente. $\mathrm{O}$ segundo modelo, predominante no período medieval, é marcado por um processo de marginalização, em que as crianças nascidas com diferenças funcionais eram mantidas às margens do convívio social, vivendo em asilos (PALACIOS, 2008). 
A partir do século XVII, a centralidade do pensamento científico passa a influenciar a compreensão das diferenças funcionais, as quais passam a ser identificadas como questões de saúde, passíveis de tratamento. O aperfeiçoamento de conhecimentos sobre as causas das diferenças funcionais promoveu grandes mudanças na forma de compreendê-las, que deixaram de ser entendidas como resultado de açôes divinas e passaram a ser compreendidas como fatos científicos, explicados biomedicamente. Outra mudança se localiza nas relaçóes sociais, posto que as pessoas com diferenças funcionais deixam de ser consideradas desnecessárias socialmente, porque com o aparato científico elas podem ser normalizadas, inaugurando, assim, o modelo reabilitador (PALACIOS, 2008).

É apenas na passagem do século XIX para o XX que o modelo social surgirá, com base em aportes de conhecimentos advindos das Ciências Sociais e da Psicologia, trazendo consigo a compreensão que as diferenças funcionais não podem ser entendidas como limitações individuais, mas como expressão das dificuldades de a sociedade reconhecer e atender as especificidades das pessoas com diferenças funcionais. Assim, o foco da deficiência não está na ausência ou no prejuízo de funcionalidade, mas na falta de oferta de meios de vida (comunicação, mobilidade, atitude, etc.) que garantam condições dignas de participação social.

Os modos de pensar as diferenças funcionais não são modelos estanques, pelo contrário, são ideários que coexistem, ganhando mais ou menos força em distintos momentos, sendo defendidos ou repudiados por diferentes setores da sociedade, ou seja, coexistem forças que defendem a eliminação, o isolamento, a normalização e a produção social de meios para a participação social dessa população. Tais forças agem na disputa da legislação, da formulação de políticas, no desenho de serviços de atenção e na definição de verbas.

O percurso teórico realizado por Palacios (2008) entrelaça-se com a história da Educação Especial. No Brasil, Bueno (2009) ressalta que as primeiras iniciativas de atendimento especializado foram realizadas em espaços segredados, sob um modelo consolidado pela crença de que a separação evitaria a presença de pessoas consideradas anormais interferissem nas relaçôes racionalizadas no espaço urbano e também cria a ideia de proteçáo dos sujeitos, que ao estarem segregados em uma instituição, estariam protegidos dos preconceitos da sociedade e contariam com a atenção profissional adaptada às suas necessidades. $\mathrm{O}$ autor salienta, ainda, que a falta de vagas nas instituiçôes de Educação Especial fez com que a possibilidade de internação nesses institutos fosse encarada como um privilégio.

Esse tipo de oferta educacional prevaleceu até o início do século XX, quando diferentes instituições de Educação Especial foram inauguradas no país oferecendo serviços compensatórios, caráter filantrópico, fundados no modelo de reabilitaçáo, descrito por Palacios (2008).

Novas formas de atendimento foram sistematizadas pelo Movimento de higiene mental, que priorizou a disseminação de práticas médicas e de outras terapêuticas, buscando prevenir o surgimento de comportamentos considerados inadequados e 
também identificar as crianças com deficiência (COTRIN, 2010; PATTO, 2015). A oferta de serviços de Educação Especial estruturava-se a partir da elaboração de diagnósticos médicos, peças-chave para a oferta de práticas de correção, sem uma efetiva preocupação com o desenvolvimento e a aprendizagem da criança (COTRIN, 2010).

O ideário das classes homogêneas, preconizado pelo Movimento da Escola Nova, contribuiu para a adoção de práticas avaliativas e diagnósticas, cuja mensuração da inteligência e do nível de maturidade da criança tornou-se prática corrente no cotidiano escolar, respalda pela ideia de prevenção do surgimento de problemas de aprendizagem (COTRIN, 2010).

Ainda no contexto de atuação do movimento escolanovista, Patto (2015) salienta que a Psicologia, ao aproximar-se da Pedagogia, promoveu distorções em alguns princípios da Escola Nova, dentre eles a substituiçáo do planejamento educacional realizado a partir das características do desenvolvimento infantil para o ensino baseado nos resultados das avaliaçôes psicométricas. Tal mudança desloca os determinantes escolares para as crianças, de forma individual, sem considerar os aspectos relativos à proposta educacional e ao ensino.

A expansão dos serviços públicos e da rede privada-assistencial de Educação Especial no país teve início na década de 1950 e estende-se até a atualidade. A ampliação da rede de atendimento também ampliou as categorias compreendidas no espectro da anormalidade, fazendo com que um amplo conjunto de pessoas, anteriormente náo identificadas, passassem a fazer parte dos quadros de diagnóstico nosológico.

A ampliação do número de escolas públicas no país está fortemente relacionada à inclusão de crianças multi-repetentes sem indícios significativos de deficiência intelectual, fazendo com que as chamadas dificuldades de aprendizagem sejam compreendidas como questóes específicas do sujeito, levando à cessaçáo das possibilidades de reflexáo sobre o papel da instituiçáo escolar na produçáo do fracasso escolar (BUENO, 2009; VELTRONE, MENDES, 2011).

A retomada de tais aspectos históricos permite-nos identificar a lógica em que se assenta a política de Educação Especial no país e traçar relações entre as principais características dos fios que tecem as proposiçôes. A concomitância de diferentes modelos de compreensão das diferenças funcionais persiste, há resquícios do modelo segregacionista, em açóes e disputas que envolvem os serviços prestados por instituiçóes especializadas. $\mathrm{O}$ modelo reabilitador se presentifica em diferentes instâncias, tanto nos modos de definir o público-alvo, quanto nas formas de avalição, realizadas a partir dos saberes do campo biomédico. A inserção dos conhecimentos e práticas voltados para o modelo social de compreensão das diferenças funcionais é incipiente nas políticas de educação especial, pois ainda é preciso criar estratégias de efetiva participação de todas/todos nas mais diferentes instâncias de decisão sobre os planos e programas educacionais. As açóes de combate ao fracasso escolar e a construção de políticas de Educação Especial constituíram-se a partir de uma base uníssona, cujo atendimento individualizado, realizado a partir das avaliaçóes de desempenho da criança, tornou-se a forma preconizada, em detrimento de estratégias elaboradas a partir da avaliaçáo do processo ensino-aprendizagem em situaçóes coletivas de colaboração entre estudantes. 
Ocorre, nesse processo, o apagamento da figura da/do professora/professor no processo de construção das políticas educacionais gerais e das políticas de Educação Especial. Da mesma maneira, ocorre a invisibilização dos aspectos relativos à sala de aula e das questôes ligadas ao financiamento da educação, com implicaçôes diretas nas condiçóes de ensino e de aprendizagem (LEHER, 2013, p.272-3).

A implantação das propostas elaboradas pelo Banco Mundial promoveu uma redução dos investimentos educacionais, ofertando o financiamento mínimo, chamado de minimum learning basic (SILVA, 2003). Tal proposição baseia-se na redução dos custos em Educação, enfatizando os programas de formação continuada em detrimento da formação inicial, assim como a sistematização de compras de recursos materiais para escolas, sem realizar qualquer programa voltado para a melhoria das condiçóes de trabalho das/dos professoras/professores (FONSECA, 2001).

A sistematização dessas políticas trouxe consigo uma abertura para a entrada e a permanência da lógica medicalizante no cenário escolar, como forma de explicar a não aprendizagem das crianças na escola. Essa explicação é marcada pelo processo de despolitização, tanto da escola quanto da sociedade em geral, fazendo com que os problemas que surgem na escola sejam atribuídos exclusivamente aos indivíduos, mais especificamente ao aparato e funcionamento cerebral das/dos estudantes. Deslocamento perfeito para a penetração do ideário neoliberal.

Tal processo é descrito por Moysés e Collares (2010) a partir do conceito de medicalização da Educação, cuja definição é a redução de questôes sociais, culturais, econômicas e políticas à dimensão médica, compreendida a partir do corpo biológico. As únicas formas de intervenção para a resolução da problemática ocorrem apenas a partir do plano individual ou familiar, excluindo as relaçóes com a dimensão coletiva, social, política e econômica da problemática.

A hegemonia do ideário medicalizante no contexto educacional, discutida por Collares e Moysés (1997) expropria a/o professora/professor de sua própria prática. Os saberes pedagógicos sáo silenciados, assim como as possiblidades de intervençôes baseadas na concretude da escola, nas relaçôes estabelecidas entre os diferentes agentes sociais e na participação democrática da comunidade escolar nas decisóes e caminhos a serem traçados.

O processo de medicalização se entrelaça com os modelos de avaliação individual implementados no início do século XX, em que se procura prever riscos e sistematizar correçôes futuras. Essa tendência faz com que as escolas priorizem, em seus planejamentos, metodologias e práticas avaliativas o modelo das avaliaçôes externas, em detrimento da realização de avaliaçôes que consideram o contexto educacional.

Assim, determinadas políticas educacionais podem adquirir caráter medicalizante na medida em que apagam as problematizaçóes referentes às condiçôes materiais das escolas, aos salários das/dos professoras/professores, a origem e o capital cultural das/dos estudantes, enfocando a utilizaçáo de "tecnologias do não aprender", tanto no que diz respeito ao sucesso nas avaliaçôes escolares quanto à produção de crianças ditas doentes, submetidas aos ditames da indústria farmacêutica (LEHER, 2013). 
A política de Educação Especial é composta por diferentes marcos regulatórios; o principal é a Política Nacional de Educação Especial na perspectiva da Educação Inclusiva, publicada em 2008. Tal documento faz um percurso histórico dos serviços de Educação Especial no país, traz informaçôes referentes ao aumento do número de matrículas de alunos/as que compóem o público-alvo da Educaçáo Especial e apresenta, então, as bases em que se assenta a política. O documento ressalta a Educação Especial como uma modalidade que perpassa todos os níveis de ensino, responsável pela oferta de atendimento educacional especializado e pela criação de recursos e estratégias para o atendimento na sala comum das escolas regulares. A política versa também sobre a formação e conhecimentos da/do professora/professor especializada.

Conforme salienta Angelucci (2014), a política de Educação Especial, como não poderia deixar de ser, já que é produto da correlação de forças presente na sociedade, está marcada pela lógica medicalizante, revelando-a, inclusive, de forma contundente, na definição do público-alvo da Educação Especial a partir de categorias diagnósticas oriundas do campo da Saúde, em uma perspectiva biomédica.

As leis $\mathrm{n}^{\circ} 10.098$ de 19 de dezembro de 2000 e $\mathrm{n}^{\circ} 10.436$ de 24 de abril de 2002 também representam importantes avanços para a garantia do direito à Educação. A primeira versa sobre os principais critérios para a acessibilidade de pessoas com deficiência e a segunda refere-se à garantia de acesso à Língua Brasileira de Sinais (Libras). Mais recentemente a Lei Brasileira de Inclusão da Pessoa com Deficiência, promulgada em 2015, inspirada na Convenção internacional dos direitos das pessoas com deficiência (2008), ampliou as discussôes sobre autonomia, acesso a espaços e tecnologias, bem como a recursos educacionais, a fim de promover o aprendizado da/ do estudante, instaurando, pela primeira vez na história do Brasil, a regulamentação dos direitos dessa populaçáo sob o marco dos direitos humanos (PALACIOS, 2008).

\section{Objetivos}

O objetivo do trabalho foi compreender como as políticas públicas de Educação e, mais especificamente, de Educação Especial têm sido descritas, buscando observar em que situaçóes se fazem presentes e que tensionamentos e contradiçóes expressam os indícios da lógica medicalizante, analisando tanto a legislação, quanto os documentos e diretrizes oficiais elaborados pelo Ministério da Educação.

\section{Metodologia}

Os documentos foram analisados a partir dos princípios do paradigma indiciário, sistematizado por Ginzburg (1989). Esse referencial considera as concepçóes presentes nas políticas educacionais, buscando identificar sinais e pistas que revelam a permeabilidade ou não dos documentos a concepçóes medicalizantes. Permite ainda a reflexão sobre a correlaçáo de forças que seus tensionamentos e contradiçóes expressam.

Dentre os documentos analisados estão: a Política Nacional de Educação Especial na perspectiva da Educação Inclusiva, o documento final da Conferência $\mathrm{Na}$ cional de Educação (Conae), o Plano Nacional de Educação (PNE). 


\section{Resultados}

Os documentos analisados tratam de variados aspectos da Educação. O primeiro, publicado em 2008, refere-se à Educação Especial, abordando seu histórico, seus marcos legais, a definição de seu público-alvo, para, então, discutir as diretrizes para a escolarização em uma perspectiva inclusiva, enfatizando aspectos da formação docente e da estruturaçáo do ensino em classes comuns, com subsídio do atendimento educacional especializado. O segundo documento analisado é a versão final da Conae de 2014, resultado das deliberaçôes advindas das discussões realizadas em âmbito municipal e intermunicipal, estadual, distrital e nacional sobre o Plano Nacional da Educação. Tal movimento deriva da articulação do Sistema Nacional de Educação: participaçáo popular, cooperação federativa e regime de colaboraçáo, definidos previamente pela Conae de 2010. As discussões foram divididas em sete eixos, sendo que será aqui realizada a análise do eixo II, o qual versa sobre a Educação e a Diversidade: justiça social, inclusão e direitos humanos. Já o PNE, aprovado em 2014, versa sobre as vinte metas a serem alcançadas para a próxima década. A meta número quatro desse documento versa sobre a garantia de acesso e qualidade do ensino para alunas/ alunos público-alvo da Educação Especial, constituindo-se, assim, em objeto da análise aqui empreendida.

A Política Nacional de Educação Especial na perspectiva da Educação Inclusiva, retoma as bases históricas dos serviços de Educaçáo Especial no país, além de mapear as convençóes internacionais de que o Brasil é signatário. O documento institui mudanças na forma de atendimento de estudantes identificadas/os como público-alvo da Educação Especial ao problematizar o ensino segregado ofertado tanto por instituições especializadas, quanto por escolas especiais e classes especiais localizadas em escolas regulares. Esse documento propóe a oferta do atendimento educacional especializado como uma modalidade transversal que percorre todos os níveis de ensino como um serviço complementar ou suplementar ao ensino comum, salientando que $o$ atendimento educacional especializado não pode ser ofertado como um serviço substitutivo ao ensino regular. De modo geral, constitui um avanço importante para a garantia do acesso de crianças e adolescentes com diferenças funcionais na escola regular e aos serviços especializados.

Contudo, como já afirmado por Angelucci (2014, p.124) é possível identificar a presença lógica medicalizante na referida Política, na medida em que adota termos do campo biomédico para definir quem será seu público-alvo. Ao nomear como parte de seu público-alvo as pessoas com diagnóstico de transtornos globais do desenvolvimento sem discutir o sentido desse recorte e sem discutir as interfaces entre Saúde Mental e Educação, acaba, simplesmente, por alimentar um mecanismo de porta de entrada na Educação Especial que é a presença de laudo com o referido diagnóstico. Tanto é assim que em 2014 foi lançada a Nota Técnica MEC/Secadi ${ }^{3}$ No. 04, que afirma a desnecessidade de laudo diagnóstico, orientando que a decisão sobre a compreensão de uma/um estudante como parte do público-alvo da Educação Especial deve se dar mediante realização de grupo de estudos de caso entre educadoras/es da unidade educacional frequentada pela/o estudante, podendo-se consultar as/ 
os profissionais de Saúde envolvidas/os. Ora, há que se perguntar quais as condições teórico-práticas que educadoras/es possuem para chegar à conclusão de que uma/ um estudante tem transtorno global do desenvolvimento, se essa é uma classificação nosológica construída desde os saberes biomédicos? Assim, o que ocorre é a produção de uma cilada em que se afirma a autonomia da escola para se decidir sobre a compreensão de uma/um determinada/o estudante como público-alvo da Educação Especial, mas que, para tanto, é preciso utilizar um raciocínio extrínseco aos saberes educacionais para que se chegue a um diagnóstico nosológico. Diante desta cilada, tem sido uma saída comum que as escolas apenas subscrevam laudos de profissionais da Saúde.

Também as análises do documento final da Conae revelam avanços significativos nas discussóes voltadas para o atendimento das/dos estudantes em suas especificidades, respeitando o ritmo e as características de cada uma/um, bem como organizando estratégias para a garantia do direito ao acesso e à permanência nos diferentes níveis de educação. O documento enfatiza a construção de práticas que favoreçam o respeito à diversidade, contemplando as discussôes sobre diferenças funcionais, identidade de gênero, raça/etnia, povos quilombolas, orientação sexual, tolerância religiosa, etc.

Dentre as principais propostas, estão a inclusão de temáticas relativas à diversidade nos cursos de formação inicial e formação continuada de professoras/professores, bem como o incentivo à realização de pesquisas acadêmicas sobre a diversidade. Simultaneamente às propostas de respeito à diversidade no que se refere ao ritmo e aos modos de aprender de cada sujeito, organizam-se também proposiçóes voltadas para identificação e avaliação das/dos estudantes que poderiam ser enquadradas/os pelos diagnósticos nosológicos que se desenvolvem no espaço escolar.

As propostas do documento envolvem tanto a elaboração de políticas de ação afirmativa para o ingresso e a permanência de estudantes público-alvo da Educação Especial em todos os níveis de ensino, incluindo graduação e pós-graduação, quanto a elaboração de metodologias e disponibilização de materiais didáticos específicos.

Com isso, o documento revela também indícios da lógica medicalizante ao tratar das/os alunas/os público-alvo da Educação Especial, sem fazer quaisquer ponderaçōes e reflexões sobre esse grupo e sobre as questôes que produzem o fracasso escolar, tendo como referência atuaçóes individualizantes, e, por conseguinte, medicalizantes. Moysés e Collares $(2010,2013)$ nos ajudam a compreender a construção de algumas categorias nosológicas, também denominadas pelas autoras como supostos transtornos que, ao serem localizados no aparato e funcionamento cerebral do indivíduo, cessam as possibilidades de discussão e reflexão sobre o espaço em que tais transtornos surgem. Ademais, foi possível observar no documento a menção a outras categorias diagnósticas, dentre elas o Tdah e as dificuldades de aprendizagem, tomando-os como categorias auto-explicativas e sem articulá-las a contextos educacionais.

Em relação ao PNE, cabe ressaltar a proposição de diferentes açôes voltadas para o público-alvo da Educação Especial. Dentre elas estão: a organização de salas de recursos multifuncionais, a oferta de disciplinas nos cursos de licenciatura e de 
pós-graduação que trabalhem com as especificidades dos processos de ensino-aprendizagem e com metodologias de ensino voltadas para as/os estudantes público-alvo da Educação Especial, assim como o desenvolvimento de materiais didáticos e tecnologia assistiva para a garantia da acessibilidade e aprendizagem.

A sistematização das estratégias envolve também a ampliação das equipes para o atendimento da demanda de escolarização, como a contratação de professoras/es para atendimento educacional especializado, profissionais de apoio, tradutoras/es ou intérpretes de Libras, guias-intérpretes para alunas/alunos com surdo-cegueira, professoras/es de Libras, prioritariamente surdas/os e também professoras/es bilíngues (BRASIL, 2014).

O documento afirma ainda como estratégia para a garantia de oferta de Educação de qualidade a criaçáo de centros multidisciplinares de apoio, pesquisa e assessoria com profissionais da área da Saúde, psicólogas/os e assistentes sociais, articuladas/ os com universidades, para apoiar as/os professoras/es que atuam na Educaçáo Básica com alunas/os público-alvo da Educação Especial. A elaboração e a operacionalização de tal proposta implica uma profunda reflexão sobre as práticas educacionais e a relação Saúde/Educação, sobretudo, no que diz respeito à influência dos saberes da Medicina sobre os saberes da Educação.

A disputa pela oferta de serviços de Educação Especial por entidades e instituiçôes especializadas está presente na formulação da meta quatro do PNE que, após muitas batalhas, foi aprovada com a seguinte redação:

Universalizar, para a população de quatro a dezessete anos com de-
ficiência, transtornos globais do desenvolvimento e altas habilida-
des ou superdotaçáo, o acesso à educaçáo básica e ao atendimento
educacional especializado, preferencialmente na rede regular de
ensino com a garantia de sistema educacional inclusivo, de salas
de recursos multifuncionais, classes, escolas ou serviços especiali-
zados, públicos ou conveniados (BRASIL, 2014).

O retorno do termo "preferencialmente" marca um retrocesso na implantação da plítica de 2008, que se enfatiza a oferta de serviços especializados em escolas regulares. O PNE não conseguiu avançar na discussão e na garantia de serviços especializados ofertados ampla e exclusivamente nas escolas regulares, o que permitiria maiores aproximaçóes entre sala comum e atendimento educacional especializado, proporcionando troca de saberes e experiências, sobretudo, na criaçáo de propostas educativas que compreendem o sujeito da aprendizagem como um ser integral.

As dificuldades em garantir o espaço da escola pública a todas/os constituem um contexto em que a lógica medicalizante, ora é superada, ora estabelece-se nas propostas e diretrizes educacionais.

\section{Considerações}

As discussões que envolvem as políticas públicas em Educação Especial são amplas e complexas, formadas por distintas concepçóes. A consideração dos textos que versam sobre a política nacional de Educação Especial vigente e dos trechos que remetem a aspectos da Educação Especial na Conae e no PNE permite afirmar 
a concomitância de dois modelos descritos por Palacios (2008), o reabilitador e o modelo social.

O primeiro perpetua-se em ações pautadas em intervençôes individuais, sem articular-se a reflexões sobre mudanças no contexto educacional, na reorganização do trabalho, nos discursos e nas práticas, além da presença de termos biomédicos na categorização de estudantes, a partir da qual se organiza a oferta de serviços. A própria adesão à terminologia "deficiência, ainda que justificada por ser a vigente em documentos nacionais e internacionais, quando desacompanhada de reflexão, acaba por reiterar a ideia de falta, de ineficiência, remetendo, sem mediação, a algo que precisa ser aprimorado, consertado.

O segundo modelo se materializa a partir de conquistas e avanços importantes na garantia de direitos ao acesso à escola, sobretudo no que se refere à necessidade de produção de flexibilizações e inovações curriculares para que todas/os possam ter acesso ao conhecimento e também no que se refere à promoção do respeito às diferenças humanas como fundamento da experiência escolar.

No atinente à presença de categorias nosológicas para caracterizar de estudantes e organizar a oferta de serviços educacionais, cabe destacar a ausência de problematização, nos três documentos sobre o processo de medicalização. Como Patto (2015), Moysés (2001) e Collares e Moysés (2015) bem têm observado em suas produções nos últimos trinta anos, os desafios relativos à escolarização e ao fracasso escolar, muitas vezes, são explicados tanto por profissionais da Saúde quanto por profissionais da Educação a partir de relaçôes de causalidade biológica ou relativa às relaçôes familiares das crianças, promovendo um tamponamento das discussōes sobre o processo de escolarizaçáo e o projeto de Educação em curso no país.

Além da apropriação de termos biomédicos, Moysés e Collares (2010) problematizam a transformação de fenômenos educacionais em sintomas que indicariam, por sua vez, supostos transtornos dos sujeitos, como, por exemplo, a dislexia e o Tdah. Reduzidas a sintomas individuais, tais questôes deixam de encontrar na escola e entre educadoras/es potência de compreensão e enfrentamento, para tornarem-se mero encaminhamento a profissionais da Saúde, em uma busca contínua de terapêuticas (medicamentosas ou não) que apenas retroalimentam a perspectiva de reabilitação.

A contenção de sintomas, a busca da reprogramação de comportamentos, em detrimento da percepção apurada dos dilemas cotidianos e da produção de estratégias calcadas nas experiências educacionais, acabam novamente por dar continuidade às mediçôes da inteligência e outras estratégias com fim de segregação. Nesse sentido, é possível afirmar que a presença do modelo reabilitador, ademais de não impulsionar o ideário inclusivo nas escolas, reitera a integração como proposta educacional, posto que condiciona o direito à Educação à adesão a terapêuticas individuais, partindo-se da leitura de que há um problema de escolarização devido a uma funcionalidade inadequada do sujeito, seja da ordem cognitiva, comportamental ou afetiva. 
Assim, naquilo que se refere à Educação Especial, observa-se a busca por compreender seu público-alvo como sujeitos com condiçôes específicas, que não impedem sua aprendizagem, devendo ser detectadas as barreiras sociais que obstaculizam a garantia de seus direitos. Entretanto, muitas vezes, os mesmos documentos, ao retomarem a caracterização de estudantes a partir de diagnósticos nosológicos, recaem no discurso culpabilizador, que vê na especificidade do corpo ou da função um limitador para a aprendizagem. Culpabilização que dispara um circuito velho conhecido na educação brasileira: é preciso o laudo para definir que ação pedagógica tomar; o laudo é elaborado, mas não dialoga com o léxico da Educação ou com o cotidiano escolar; alimenta-se a expectativa de que as terapêuticas transformem a/o estudante; as terapêuticas não têm impacto significativo sobre o cotidiano escolar.

Os três documentos analisados ressaltam a importância da construção de práticas coletivas, democráticas para o enfrentamento das questôes educacionais. Afirmam a garantia de acesso universal aos diferentes níveis da Educação Básica, articulando estratégias para formação de professoras/es e para a organização de serviços de atendimento às/aos estudantes.

No concernente à Educação Especial, há contradições entre a busca de garantia de acesso a serviços de qualidade e a falta de discussôes e problematizaçôes sobre a presença do ideário medicalizante, revelando o quanto as políticas públicas inserem-se em um campo de disputas no qual forças empenhadas em buscar avanços na superação das desigualdades sociais convivem com forças que medicalizam e culpabilizam as/os estudantes.

O documento final da Conae e o PNE náo conseguiram superar as propostas e as lacunas da Política Nacional de Educação Especial na perspectiva da Educação Inclusiva, muitas vezes, retomando a lógica biomédica para justificar a necessidade da Educação Especial, sob uma perspectiva que busca no sujeito as explicaçôes para seu insucesso. Tal movimento evidencia a força das concepçôes medicalizantes sobre diferenças funcionais, mesmo no contexto de vigência da Convenção Internacional de Direitos das Pessoas com Deficiência e da Lei Brasileira de Inclusão da Pessoa com Deficiência, formuladas a partir do modelo social de entendimento das diferenças funcionais.

As interrelaçôes entre fracasso escolar, Educação Especial e medicalização da Educação sugerem a necessidade de ampla discussão e constante reflexão sobre as construçôes teóricas e práticas, visando à articulação de propostas educacionais que avancem na garantia do direito à Educação para todas/os, sem exceçóes ou condicionantes. Para tanto, entende-se como necessária a reconfiguração das relaçóes entre os campos da Saúde e da Educação, permitindo a construção de práticas coletivas que discutam as problemáticas escolares a partir do diálogo e não da sobredeterminação da Saúde pela Educação. Isso implica, também, esforço da Educação para produzir formas de compreender as/os estudantes e seus processos ensino-aprendizagem fora do eixo patologia/normalidade, afirmando radicalmente a diversidade humana como princípio, meio e fim do trabalho educativo. 


\section{Referências}

ANGELUCCI, C.B. Medicalizaçáo das Diferenças Funcionais - continuismos nas justificativas de uma Educaçáo Especial subordinada aos diagnósticos. Nuances: estudos sobre Educação, Presidente Prudente - SP, v. 25, n. 1, p. 116-134, jan./abr. 2014.

BRASIL. Lei $\mathrm{n}^{\circ}$ 10.098, de 19 de dezembro de 2000. Estabelece normas gerais e critérios básicos para a promoçáo da acessibilidade das pessoas portadoras de deficiência ou com mobilidade reduzida, e dá outras providências.

BRASIL. Ministério da Educação. Secretaria de Educação Especial. Lei no 10.436, de 24 de abril de 2002. Dispóe sobre a Língua Brasileira de Sinais - LIBRAS e dá outras providências. Disponível em: < http://www. planalto.gov.br/ccivil_03/leis/2002/110436.htm>. Acesso em 12 mai. 2017.

BRASIL. Ministério da Educação. Secretaria de Educação Especial. Política Nacional de Educaçáo Especial na Perspectiva da Educaçăo Inclusiva. 2008. Disponível em: < http://portal.mec.gov.br/arquivos/pdf/politicaeducespecial.pdf>. Acesso em 15 mail. 2017.

BRASIL. Decreto 6.949/2009. Promulga a Convenção Internacional dos Direitos das pessoas com Deficiência e seu Protocolo Facultativo, assinados em Nova York, em 30 de março de 2007. 2009. Disponível em: < www. planalto.gov.br/ccivil_03/_ato2007-2010/2009/decreto/d6949.htm>. Acesso em: 30 jun. 2017.

BRASIL. Fórum Nacional de Educação. Documento Final da Conae 2014. Disponível em: <http://fne.mec. gov.br/images/doc/DocumentoFina240415.pdf>. Acesso em 15 jul 2017.

BRASIL. Lei 13.005, de 25 de junho de 2014. Aprova o Plano Nacional de Educaçâo e dá outras providências. Disponível em: http://www.planalto.gov.br/CCIVIL_03/_Ato2011-2014/2014/Lei/L13005.htm Acesso em 28 jun. 2017.

BRASIL. Ministério da Educação. Secretaria de Educação Continuada, Alfabetização, Diversidade e Inclusão. Nota técnica $\mathrm{n}^{\circ} 4$, de 23 de janeiro de 2014 . Orientaçáo quanto a documentos comprobatórios de alunos com deficiência, transtornos globais do desenvolvimento e altas habilidades/superdotaçáo no Censo Escolar. Disponível em: < http://portal.mec.gov.br/index.php?option=com_docman\&view=download\&alias=15898-nott04-secadi-dpee-23012014\&category_slug=julho-2014-pdf\&Itemid=30192 >. Acesso em 03 jul. 2017.

BRASIL. Lei 13.146 de 06 julho de 2015. Institui a Lei Brasileira de Inclusáo da Pessoa com Deficiência Estatuto da Pessoa com Deficiência. Disponível em: http://www.planalto.gov.br/ccivil_03/_Ato20152018/2015/Lei/L13146.htm. Acesso em 28 jun. 2017.

BUENO, J. G. S. A produção social da identidade do anormal. In: FREITAS, Marcos Cezar de (Org.). História Social da Infância no Brasil. São Paulo: Cortez, 2009.COLLARES, C. A. L.; MOYSÉS, M. A. A. Preconceitos no cotidiano escolar: ensino e Medicalização. São Paulo. Ed. Autor, 2015.

COTRIN, J. T. D. Itinerários da psicologia na Educaçáo Especial: uma leitura crítica em psicologia escolar. 2010. 180 f. Tese (Doutorado em Psicologia Escolar e do Desenvolvimento Humano) - Instituto de psicologia da Universidade de São Paulo, USP, Sáo Paulo, 2010. Disponível em: < http://www.teses.usp.br/teses/disponiveis/47/47131/tde-22072010-091001/pt-br.php>. Acesso em 02 jul. 2016.

FONSECA, Marília. A experiência de cooperaçáo entre o Brasil e o Banco Mundial: redefinindo o papel da educaçáo e do professor. Linhas Críticas, Brasília, v. 7, n. 12, jan/jun 2001. Disponível em: < http://periodicos. unb.br/index.php/linhascriticas/article/view/6643> Acesso em 04 jul. 2016.

GINZBURG, C. Sinais: Raízes de um Paradigma Indiciário. In: Mito, Emblemas, Sinais: Morfologia e História. São Paulo: Companhia das Letras, 1989.

LEHER, R. Medicalizaçáo de políticas públicas, avaliaçáo e metas de desempenho. In: COLLARES, C.L.A.; MOYSÉS, M.A.A.; RIBEIRO, M.C.F. (Orgs.). Novas Capturas, Antigos Diagnósticos na Era dos Transtornos. Campinas, SP: Mercado de Letras, 2013.

MOYSÉS, Maria Aparecida. A Institucionalizaçáo do Invisível: Crianças que não-aprendem-na-escola. Campinas, SP: Mercado de Letras, 2001.

MOYSÉS, Maria Aparecida A.; COLLARES, Cecília. A.L. Dislexia e TDAH: uma análise a partir da ciência médica. In: Conselho Regional de Psicologia, Grupo Interinstitucional Queixa Escolar (Orgs.). Medicalizaçấo de Crianças e Adolescentes: conflitos silenciados pela reduçấo de questốes sociais a doenças de indivíduos. São Paulo: Casa do Psicólogo, 2010. 
MOYSÉS, Maria Aparecida A.; COLLARES, Cecília. A.L. Medicalização: O obscurantismo reinventado. In: COLLARES, C.L.A.; MOYSÉS, M.A.A.; RIBEIRO, M.C.F. (Orgs.). Novas Capturas, Antigos Diagnósticos na Era dos Transtornos. Campinas, SP: Mercado de Letras, 2013.

PALACIOS, Augustina. El modelo social de discapacidad: orígenes, caracterización y plasmación en la Convención Intenacional sobre los Derecos de las Personas con Discapacidad. Madrid: Grupo editorial CINCA, 2008

PATTO, M.H. S. A Produçáo do Fracasso Escolar: Histórias de Submissão e Rebeldia. São Paulo: Intermeios, 2015.

SILVA, M. A. Do projeto político do banco mundial ao projeto político-pedagógico da escola pública brasileira. Cad. Cedes, Campinas, v. 23, n. 61, p. 283-301, dez 2003. Disponível em: < http://www.scielo.br/ $\mathrm{pdf} /$ ccedes/v23n61/a03v2361.pdf>. Acesso em 30 jun. 2016.

VELTRONE, A. A.; MENDES, E. G. Descrição das propostas do Ministério da Educação na avaliaçáo da deficiência intelectual. Paidéia, v. 21, n. 50, 2011. Disponível em: < http://www.scielo.br/pdf/paideia/ v21n50/14.pdf>. Acesso em 14 jul. 2016.

\section{Notas}

${ }^{1}$ Esta pesquisa conta com financiamento da Capes (processo 1551812).

${ }^{2}$ Em substituiçăo à terminologia deficiência, a utilizaçăo de diferenças funcionais vem sendo proposta desde 2004, por ocasião do $5^{\circ}$ Encontro Internacional do Movimento Vida Independente, ocorrido na Espanha. Tal transformação reconhece a diversidade das possibilidades de organizaçôes sensoriais, motoras e cognitivas, enfatizando as diferenças, sem reportá-las ao campo biomédico e/ou a um ideal normofuncional, dimensionando-as no campo de possibilidades da experiência humana.

${ }^{3}$ MEC - Ministério da Educação. Secadi - Secretaria de Educação Continuada, Alfabetização, Diversidade e Inclusão. Criada em 2004, a Secretaria de Educação Continuada, Alfabetizaçấo e Diversidade foi ampliada em 2011, abrangendo também assuntos referentes à Inclusão escolar, que anteriormente era atribuição da extinta Secretaria e Educação Especial (Seesp), passando a chamar-se Secadi. Em 2016, após a destituição da presidenta eleita, a opçăo do governo em exercício tem sido a de esvaziar a referida Secretaria, demitindo profissionais que estavam na condução de projetos e programas.

\section{Correspondência}

Kelly Cristina dos Santos Silva - Universidade de São Paulo. Av. Prof. Lineu Prestes - Butantã, CEP: 03178200. São Paulo, Brasil.

E-mail: kesantos@usp.br - b.angelucci@usp.br

Recebido em 20 de setembro de 2017

Aprovado em 8 de março de 2018

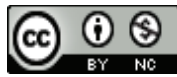

This work is licensed under a Creative Commons Attribution-NonCommercial 4.0 International (CC BY-NC 4.0) 